\title{
Forestry carbon dioxide projects to close down
}

The US Department of Energy has decided to close several large-scale, open-air projects designed to evaluate how increased concentrations of carbon dioxide affect forests. The move is necessary, many researchers say, to free up funds for a new generation of more sophisticated experiments.

Free-Air $\mathrm{CO}_{2}$ Enrichment (FACE) experiments pump carbon dioxide into the air to raise the local concentration of the gas in forests, grasslands and agricultural fields. Forest sites are particularly ambitious and expensive: Ram Oren, lead investigator of Duke University's FACE project in Durham, North Carolina, estimates that every year the experiment's four giant rings of carbon-dioxide-emitting pipes use bottled gas costing US\$900,000. The site, which began operating in 1996 and is the oldest of the forest FACE projects scattered around the world, has been used to study tree growth and productivity under conditions of at least 550 parts per million of carbon dioxide nearly 1.5 times higher than present levels.

But lead researchers at two FACE sites Duke's loblolly pine experiment and the Oak Ridge National Laboratory's sweetgum plantation in Tennessee - were told in September to prepare for closure around 2011. Other sites are already closing (see table for examples).

On one level, the closures are painful for a scientific community that craves long-term data. "I'm puzzled," says Oren. "You build FACE experiments to study ecosystem processes, and some of those are very slow." But many also view them as necessary given limited research budgets.

The Department of Energy spends up to $\$ 3$ million a year on the Duke site, \$2 million of which goes to Brookhaven National Laboratory in New York for supplies of carbon dioxide and engineering support. In 2006, an agency

\section{OPEN-AIR CARBON DIOXIDE EXPERIMENTS, PAST AND PRESENT}

\begin{tabular}{|l|l|l|l|l|}
\hline Site & Ecosystem & Plot diameter & Started & Current status \\
\hline $\begin{array}{l}\text { Durham, North } \\
\text { Carolina }\end{array}$ & Loblolly pine (Pinus taeda) forest & 30 metres & 1996 & Closure in 2011-12 \\
\hline $\begin{array}{l}\text { Rhinelander, } \\
\text { Wisconsin }\end{array}$ & Aspen (Populus spp.) forest & 30 metres & 1997 & Closing by 2011 \\
\hline $\begin{array}{l}\text { Oak Ridge, } \\
\text { Tennessee }\end{array}$ & $\begin{array}{l}\text { Sweetgum (Liquidambar } \\
\text { styraciflua) plantation }\end{array}$ & 25 metres & 1997 & Closing by 2011 \\
\hline $\begin{array}{l}\text { Mojave Desert, } \\
\text { Nevada }\end{array}$ & $\begin{array}{l}\text { Desert scrub (Larrea tridentata, } \\
\text { Ambrosia dumosa, Lycium spp.) }\end{array}$ & 23 metres & 1997 & Harvesting now \\
\hline Viterbo, Italy & Poplar (Populus spp.) & 20 metres & 1999 & Closed in 2005 \\
\hline
\end{tabular}

CLIMATE CHANGE

Marine dead zones set to expand rapidly. www.nature.com/news advisory committee recommended the closures, citing infrastructure limitations. At Oak Ridge, the trees have grown taller than the towers that support the gas pipes; at Duke, trees in the rings have outgrown the surrounding forest, creating an 'edge effect' that could affect experimental results.

In April, the energy department sponsored a workshop to discuss the design of the next generation of FACE experiments. Those attending were hopeful that future sites could vary not only carbon dioxide concentration but other factors as well, including temperature, precipitation and nutrients. Researchers are also thinking about testing different ecosystems, particularly tropical and high-latitude forests, which are thought to be among the biggest players in the terrestrial carbon cycle.

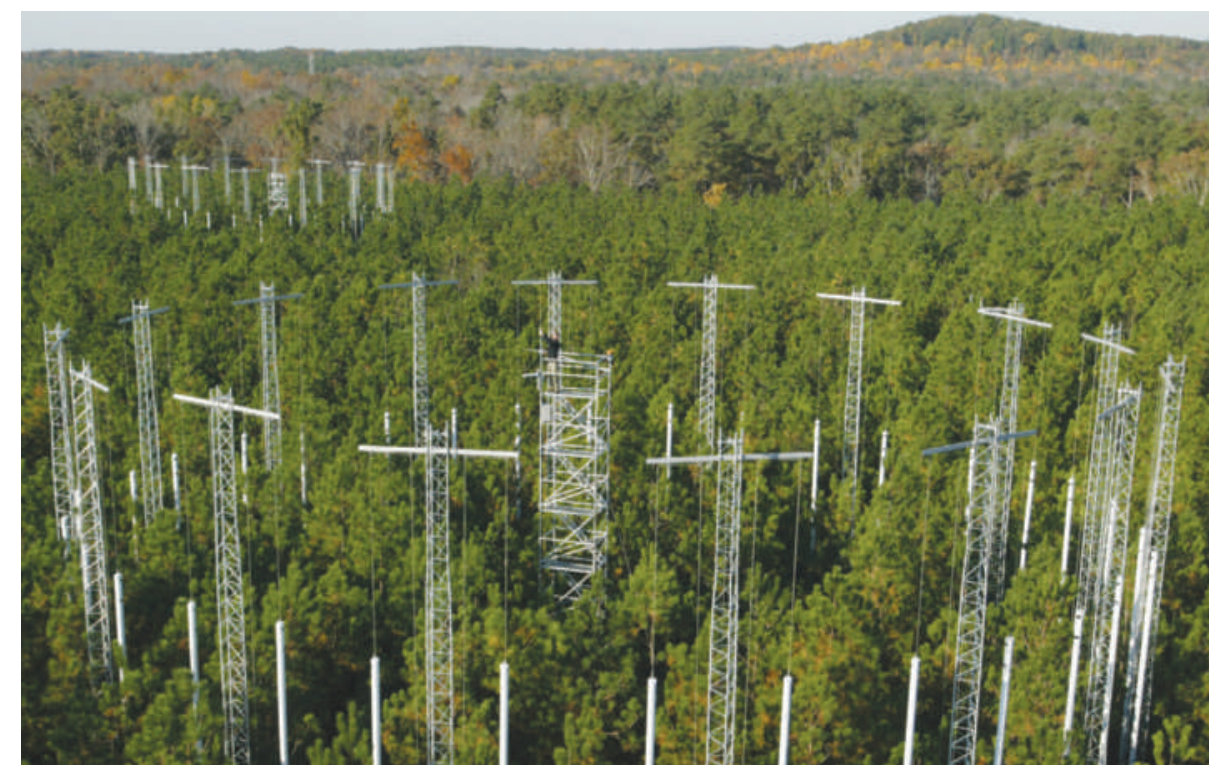
Cheap sources of carbon dioxide may be hard to find in remote areas. This could pose a particular problem in the tropics, where the bigger trees will require larger gas supplies, notes Franco Miglietta of the National Research Council's Institute of Biometeorology in Florence, Italy. And the technology does not yet exist to increase forest temperatures uniformly from root to canopy.

Meanwhile, the Duke and Oak Ridge FACE experiments continue to yield unexpected results. Richard Norby, a lead investigator on the Oak Ridge project, was nearly ready to end the project a few years ago. At that stage, he says, the data seemed consistent from year to year: higher carbon dioxide levels led to increased plant productivity. But then he noticed that the trees' response to the gas had begun to decline. Norby thinks that nitrogen limitation might be the culprit, and Oak Ridge teamed up with Duke in 2005 to study this effect in both forests.

Those experiments will not be completed in time for the planned shutdown dates. But that is part of the difficulty with setting the finish line for a long-term project, says Michael Kuperberg, programme manager for the projects at the energy department's Office of Science. "I've been around scientists my whole professional career," he says, "and I've never had one come to me and say 'I'm done.' There are always new experiments around the corner." Heidi Ledford 